\title{
Clinical Biochemistry of Cushing Syndrome in Dogs
}

\section{VASILE BOGHIAN*}

University of Agricultural Sciences and Veterinary Medicine „Ion Ionescu de la Brad” Iași, Romania, 3-8 Sadoveanu M. Alley, 700490, Iasi, Romania

Abstarct. The aim of the study is to determine clinical and paraclinical elements useful in the diagnosis of hyperadrenocorticism, given that the symptoms are varied and often similar to dermatitis or liver disease. Clinical signs in dogs with hyperadrenocorticism were especially of dermatological nature (bilateral alopecia, thin skin along with elastosis and hyperpigmentation, calcinosis cutis and muscle weakness and abdominal enlargement - ,potbelly”), accompanied by polyuria and polydipsia. Blood tests performed on 14 dogs of different breed, age and gender revealed moderate hyperglycemia $(143.4 \pm 3.3 \mathrm{mg} / \mathrm{dl})$, hypercholesterolemia $(332 \pm 2.9 \mathrm{mg} / \mathrm{dl})$, increased serum alkaline phosphatase $(378 \pm 3.8 \mathrm{UI} / \mathrm{L})$, alanine aminotransferase $(A L T=93.26 \pm 2.6 \mathrm{UI} / \mathrm{L})$, aspartate aminotransferase $($ AST $=89.72 \pm 2.3 \mathrm{UI} / \mathrm{L})$ and abnormal plasma cortisol $(50 \pm 3.5 \mathrm{ng} / \mathrm{dl})$. Thorough ultrasonography revealed hypertrophy of the adrenal glands $(2.92 \times 1.43 \mathrm{~cm})$. The histopathologic lesions include active metabolic cells (big, rich colored and strong-cored), containing lipid structures (steroids' precursors) and metabolic inactive cells (small, dark colored, pyknotic cored or rich in heterochromatin). Hyperglycemia, polyuria / polydipsia or elevated serum alkaline phosphatase without a significant increase in serum transaminases (AST and ALT) raises suspicion of Cushing's syndrome. If these biochemical diagnostic elements evolve along with dermatological signs (bilateral alopecia, hyperpigmentation, muscle weakness), the diagnosis of Cushing's syndrome is more likely.

Keywords: dog, hyperadrenocorticism, clinical biochemistry

\section{Introduction}

Although hyperadrenocorticism (Cushing syndrome) is a complex disease, with systemic clinical signs, the reason for a doctor appointment usually involves dermatological reasons; among dermatological examinations, Cushing syndrome counts $2 \%$ out of total cases $(1.5 \%$ iatrogenic and $0.5 \%$ spontaneous). Moreover, the most common clinical signs are completed by the polyuric-polydipsic syndrome, and as a result differential diagnosis should be considered, including diabetes, kidney diseases or pyometra in females [1, 2]. In fact, increased serum transaminases in animals with hyperadrenocorticism are not enlightening for the diagnosis, since this syndrome is also common to other diseases. Hence, establishing a clinical and paraclinical protocol for the hyperadrenocorticism syndrome allows submitting to an immediate treatment [3].

\section{Materials and methods}

Researches were made on 14 clinical cases, different breed, age and gender, all of them having in common dermatological signs associated with polyuria/polydipsia.

Biochemical tests were made for total cortisol through radioimmunoassay, liver transaminases (AST, ALT), alkaline phosphatase (ALP), blood glucose (GLU) and cholesterol (CHOL) through automatic biochemistry analyzer Cormay Accent 200 and specific kits (PZ Cormay SA, Wiosenna 22, 05-092 Lomianki, Poland). The structure and sizes of the liver and adrenal glands were emphasized by using ultrasonography (Aquilla Esaote Vet Pro). Eventually, 2 cases failed to live due to complications, therefore microscopic lesions of the adrenal glands were also taken into account, by using the smear test HEB (Hematoxylin-eosin-methylene Blue).

\footnotetext{
*email:vboghian@yahoo.com
} 


\section{Results and discussions}

Blood tests revealed hyperglycemia $(143.4 \pm 3.3 \mathrm{mg} / \mathrm{dl})$, hypercholesterolemia $(332 \pm 2.9 \mathrm{mg} / \mathrm{dL})$, increased transaminases (AST=89.72 $\pm 2.3 \mathrm{UI} / \mathrm{L}, \mathrm{ALT}=93.26 \pm 2.6 \mathrm{UI} / \mathrm{L})$ and alkaline phosphatase (378 $\pm 3.8 \mathrm{UI} / \mathrm{L})$ (Table 1).

Table 1. Results of the blood biochemical tests in dogs with hyperadrenocorticism

\begin{tabular}{|c|c|c|c|c|c|c|}
\hline Blood parameter & Cortisol & GLU & CHOL & ALP & AST & ALT \\
\hline Unit of measuring & $\mathrm{ng} / \mathrm{dL}$ & $\mathrm{mg} / \mathrm{dL}$ & $\mathrm{mg} / \mathrm{dL}$ & $\mathrm{UI} / \mathrm{L}$ & $\mathrm{UI} / \mathrm{L}$ & UI/L \\
\hline $\begin{array}{c}\text { Values of reference } \\
{[4]}\end{array}$ & $20-45$ & $\begin{array}{c}61.9- \\
108.3\end{array}$ & $115.6-253.7$ & $10.6-100.7$ & $8.9-48.5$ & $8.2-57.3$ \\
\hline $\begin{array}{c}\text { Determined values } \\
\text { (5) }\end{array}$ & $50.8 \pm 3.5$ & $143.4 \pm 3.3$ & $332 \pm 2.9$ & $378 \pm 3.8$ & $89.72 \pm 2.3$ & $93.26 \pm 2.6$ \\
\hline
\end{tabular}

Legend: GLU-glycemia; CHOL-cholesterolemia; ALP- alkaline phosphatase; AST-aspartate aminotransferase; ALT-alanine aminotransferase

Hyperglycemia, as well as polyuria/polydipsia, go under differential diagnosis for diabetes; in Cushing syndrome, hyperglycemia and hypercholesterolemia are directly submitted to the cortisol level released by the adrenocortical glands, and not to insulin, like in diabetes. As a result, increased plasma cortisol is an essential clue in Cushing syndrome diagnosis $[5,6]$.

Plasma cortisol showed increased values $(50.8 \pm 3.5 \mathrm{ng} / \mathrm{dl})$ which support clinical, structural and biochemical facts. In Cushing syndrome cortisol intensifies the catabolism and therefore the liver congestion, liver enlargement and increased serum activity of the transaminases. In Cushing syndrome cortisol intensifies the catabolism and therefor congestion and enlargement of the liver and increased serum transaminase activity.

In fact, ALP value is modified by the increasing cortisol; in dogs diagnosed with hyperadrenocorticism, the values were extremely high $(378 \pm 3.8 \mathrm{UI} / \mathrm{L})$. On the other hand, the alkaline phosphatase has a significant influence on the biliary pole of the hepatocyte, being affected by any change on this level. As a consequence ALP value becomes a considerable parameter for paraclinical diagnosis of hyperadrenocorticism: increased serum alkaline phosphatase associated with normal values of transaminases in patients suffering of skin diseases, makes paraclinical tests mandatory in order to diagnose hyperadrenocorticism (plasma cortisol determination or ultrasonography for the adrenal glands).

Clinical signs noticed in dogs with hyperadrenocorticism (Cushing) were mainly dermatological, associated with polydipsia, polyuria and inconstant polyphagia; it was also noticed bilateral alopecia, shineless fur, seborrheic dermatitis, comedones, cutaneous hypotrophy (thin skin with elastosis), abdominal enlargement, hyperpigmentation, skin infections, even calcinosis cutis in 3 cases out of total (Figure 1).

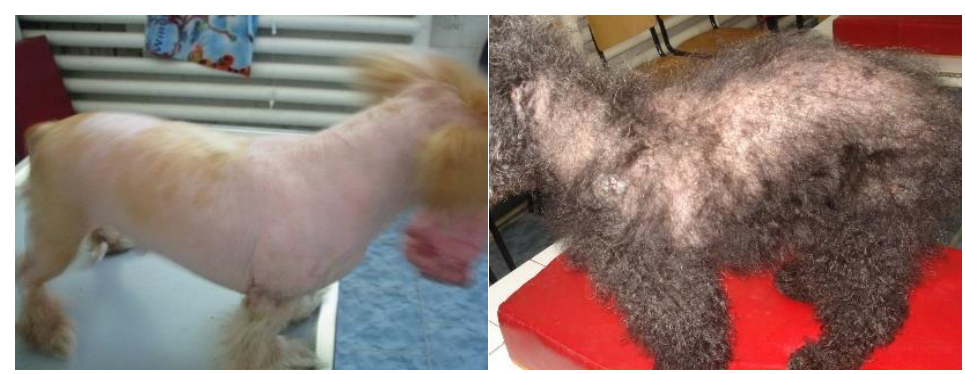

Figure 1. Clinical aspects of the Cushing syndrome (symmetrical alopecia, muscle atrophy, hyperpigmentation) 
These abnormalities come as a consequence of chronic excessive exogenous steroid administration, causing the atrophy of the seborrheic glands, bone calcium consumption, thinness of the vascular wall, intense gluconeogenesis, immunosuppression etc. [7, 8].

The forensic diagnosis disclosed diffuse calcification of the adrenal glands, liver enlargement and even a spleen hematoma. The adrenal glands' hypertrophy comes as a consequence of steroids releasing cells' stimulation from the middle zone of the adrenal cortex, being controlled by the ACTH $[9,10]$. Overdose of steroids leads to the use of bone calcium and its relocation in the soft tissues (including the adrenal gland), intensifying the liver metabolism, causing hypertrophy and thinning of the vascular walls, ending with their burst in a hematoma. The histopathological exam Hematoxylineosin-methylene Blue (HEB) stained smear of the adrenal glands revealed active metabolic cells (big, rich colored and strong-cored), containing lipid structures (steroids' precursors), as a response to an excessive release of ACTH. (Figure 2).

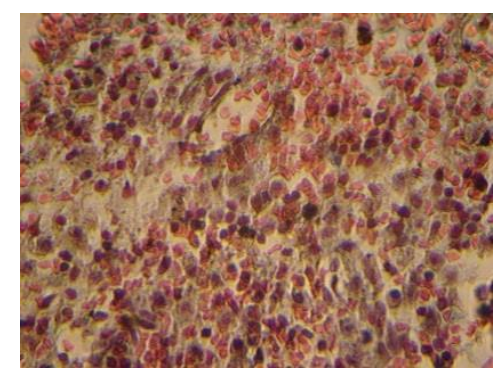

Figure 2. Histological aspects of the

Adrenal glands in dogs with

Cushing syndrome (HEBx200)

Also, metabolically inactive cells (small, dark colored, pyknotic cored or rich in heterochromatin) were noticed, as a consequence of prolonged release of ACTH and negative feed-back. At the same time, small areas of diffuse calcification were identified.

A thorough ultrasonography revealed hypertrophy of the adrenal glands $-2.92 \times 1.43 \mathrm{~cm}$ (Figure 3 ), liver congestion, liver enlargement (Figure 4) and angiocholitis.

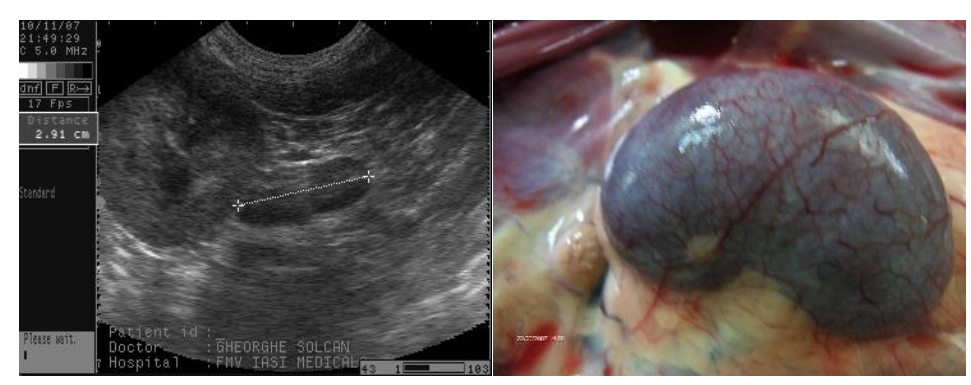

Figure 3. Ultrasound and macroscopic aspects of the adrenal glands in dogs with Cushing syndrome (hypertrophy of the adrenal gland) 


\section{Conclusions}

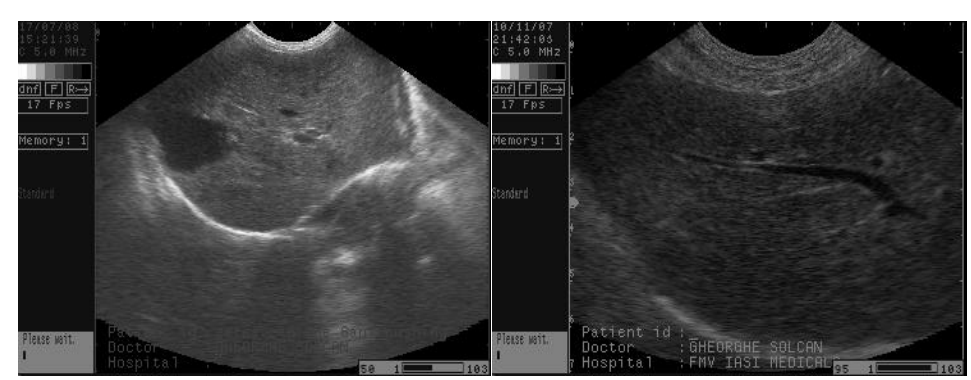

Figure 4. Ultrasound aspects of the liver in dogs with

Cushing syndrome (hepatomegaly and congestion)

Blood tests revealed moderate hyperglycemia $(143.4 \pm 3.3 \mathrm{mg} / \mathrm{dl})$, hypercholesterolemia $(332 \pm 2.9$ $\mathrm{mg} / \mathrm{dl})$, alkaline phosphatase $(378 \pm 3.8 \mathrm{UI} / \mathrm{L})$; the cortisol level was $50.8 \pm 3.5 \mathrm{ng} / \mathrm{dl}$, and moderate increased transaminases (AST=89.72 $\pm 2.3 \mathrm{UI} / \mathrm{L}, \mathrm{ALT}=93.26 \pm 2.6 \mathrm{UI} / \mathrm{L}$ ).

Increased serum alkaline phosphatase in dogs suffering off skin diseases without significant increased serum transaminases (AST and ALT) could indicate hyperadrenocorticism.

Clinical findings in dogs with hyperadrenocorticism were, especially, of dermatological nature (bilateral alopecia, thin skin along with elastosis and hyperpigmentation, calcinosis cutis and muscle weakness and abdominal enlargement - ,potbelly”), accompanied by polyuria and polydipsia.

A thorough ultrasonography revealed hypertrophy of the adrenal glands $-2.92 \times 1.43 \mathrm{~cm}$, liver congestion, liver enlargement and angiocholitis, which were later observed during the forensic exam.

The histopathological exam HEB stained smear of the adrenal glands revealed active metabolic cells (big, rich colored and strong-cored), containing lipid structures (steroids' precursors), metabolic inactive cells (small, dark colored, pyknotic cored or rich in heterochromatin) and also small areas of diffuse calcification.

\section{References}

1.ARENAS, C., PEREZ-ALENZA, D., MELIAN, C., Clinical features, outcome and prognostic factors in dogs diagnosed with non-cortisol-secreting adrenal tumors without adrenalectomy: 20 cases (1994-2009], Vet. Rec., 173, 2013, 501-504.

2.DANIELA ROXANA ALBU (MATASARIU), ELENA MIHALCEANU, ALINA PANGAL, CARMEN VULPOI, MIRCEA ONOFRIESCU, LUCIANA NITOI, ALEXANDRA MIHAILA, GABRIEL COSTACHESCU, DANIELA CONSTANTINESCU, IRINA DUMITRASCU, Can Osteopontin Be Considered a Biomarker for Endometriosis?, Rev. Chim., 68(9), 2017, 2132

3.GILOR, C., GRAVES, T.K., Interpretation of laboratory tests for canine cushing's syndrome, Top Companion Anim. Med., 26, 2011, 98-108.

4.SUSAN, E., AIELLO, B.S., The Merck Veterinary Manual eighth edition, Merck \& Co. Inc., 1998, 2192-2194.

5.CHAPMAN, P.S., KELLY, D.F., ARCHER, J., BROCKMAN, D.J., NEIGER, R., Adrenal necrosis in a dog receiving trilostane for the treatment of hyperadrenocorticism, Journal of Small Animal Practice, 45(6), 2004, 307-310.

6.SIEBER-RUCKSTUHL, N.S., BORETTI, F.S., WENGER, M., MASER-GLUTH, C., REUSCH, C.E., Serum concentrations of cortisol and cortisone in healthy dogs and dogs with pituitary-dependent hyperadrenocorticism treated with trilostane, Vet. Rec., 163, 2008, 477-481.

7.ALEXANDRA MIRICA, IOANA ANCA BADARAU, ANA MARIA STEFANESCU, RADU MIRICA, SORIN PAUN, DACIANA ANDRADA COSTINA STEFAN, DIANA LORETA PAUN, The Role of Chromogranin A in Adrenal Tumors, Rev. Chim., 69(3), 2018, 678

8.PETERSON, M.E., KINTZER, P.P., Medical treatment of pituitary-dependent hyperadrenocorticism. Mitotane, Vet. Clin. North Am. Small Anim. Pract., 27, 1997, 255-272. 
9.KINTZER, P.P., PETERSON, M.E., Mitotane (o, p‘-DDD) Treatment of 200 Dogs with PituitaryDependent Hyperadrenocorticism, Journal of Veterinary Internal Medicine 5(3), 1991, 182-190.

10.SCHWARTZ, P., KOVAK, J.R., KOPROWSKI, A., LUDWIG, L.L., MONETTE, S., BERGMAN, P.J., Evaluation of prognostic factors in the surgical treatment of adrenal gland tumors in dogs: 41 cases (1999-2005), J. Am. Vet. Med. Assoc., 232, 2008, 77-84.

$\overline{\text { Manuscript received: } 7.10 .2019}$ 